\title{
Who feeds information to regulators? Stakeholder diversity in European Union regulatory agency consultations
}

\author{
Jan Beyers* and Sarah Arras \\ Department of Political Science, University of Antwerp, Belgium \\ *Corresponding author. Email: jan.beyers@uantwerpen.be; http://www.janbeyers.eu/
}

(Received 11 September 2017; revised 12 March 2019; accepted 07 April 2019; first published online 28 May 2019)

\begin{abstract}
To design regulatory policies, agencies depend on information from the industries they are tasked to regulate. Therefore, agencies can organise consultations with the aim of obtaining information from different perspectives. This article focuses on stakeholder diversity in agency public consultations. We ask to what extent is information provided by stakeholders other than the regulated sector, such as other business interests, experts or nonbusiness interests? Stakeholder diversity is relevant as it may prevent agencies to become exposed to one-sided information and capture by specialised interests. Are there consultation design factors that foster consultation diversity? Or, is (a lack of) consultation diversity structurally shaped by the context in which an agency operates? Analysing a wide range of public consultations organised by European Union regulatory agencies indicates that most information agencies receive via consultations comes from regulated interests and that the limited participation of nonregulated interests is highly tenacious.
\end{abstract}

Keywords: agencies; consultations; European Union; interest groups; stakeholders

\section{Introduction}

In 2010, Members of the European Parliament (MEPs) voiced their concerns about the intensive lobbying of the financial sector on financial regulation and the lack of counter-mobilisation from civil society, followed by a call to establish Finance Watch, a nongovernmental organisation (NGO) that seeks to develop "counterexpertise" and promote "the public interest in financial regulation" $(2010,1)$. The MEPs explicitly stated that in se they saw no harm in the financial sector expressing its interests and supplying information to regulators, but the asymmetry in lobbying activity and the lack of expertise coming from stakeholders other than the financial sector would pose "a danger to democracy" (Finance Watch 2010, 1).

Over the past two decades, European Union (EU) regulatory policies have increasingly been delegated to independent agencies, covering a wide array of

(c) The Author(s) 2019. This is an Open Access article, distributed under the terms of the Creative Commons AttributionNonCommercial-NoDerivatives licence (http://creativecommons.org/licenses/by-ncnd/4.0/), which permits non-commercial re-use, distribution, and reproduction in any medium, provided the original work is unaltered and is properly cited. The written permission of Cambridge University Press must be obtained for commercial re-use or in order to create a derivative work. 
domains ranging from financial regulation to aviation safety and the authorisation of pharmaceuticals. ${ }^{1}$ EU regulatory agencies actively reach out to nonstate stakeholders - such as industry associations, NGOs and trade unions - to fulfil their informational needs regarding the sectors they are supposed to regulate. In general, regulators need information to identify market failures, design measures that address these failures and assess the probable consequences of the proposed regulatory measures (e.g. Coglianese et al. 2004). This need for information makes regulators highly dependent on the industries directly targeted by regulations, given an information advantage resulting from their central position within a particular field (Kwak 2014; Pagliari and Young 2016).

While information from regulated industries can lead to more effective regulatory outcomes and a smoother implementation process, regulated industries also have an incentive to gather and supply information that serves their interests, rather than the general interest (Coglianese et al. 2004; Braun 2013; Kwak 2014). Agency capture is expected to be especially high when regulators receive "strong, loud and united messages" from regulated industries, and countervailing forces, such as NGOs or labour unions, are hardly mobilised or even completely absent (Yackee and Yackee 2006; McKay and Yackee 2007, 349). Therefore, diversity in policymakers' sources of information is important, for instance, to gather information on negative externalities or hazards associated with products or production processes. As Baumgartner and Jones have stated, "information should come from as many angles as possible" when it comes to identifying and addressing complex policy problems (Baumgartner and Jones 2015, 6).

Policymakers deliberately design consultation procedures with the aim of diversifying the set of stakeholders from whom they receive information (Borrás et al. 2007). Public consultations are considered a useful tool to gather information from a diverse set of stakeholders. Given the low threshold and relatively low costs to participate, compared with face-to-face meetings with policymakers, public consultations have been promoted by the European Commission (EC) as a tool to foster the participation of nonbusiness groups such as environmental NGOs, consumer groups and labour interests (Quittkat 2011; Klüver 2012; Bunea 2017; for the United States (US) see, for instance, Furlong and Kerwin, 2005; Yackee 2006, 2013).

This article focuses on stakeholder diversity in EU agencies' public consultations and aims to answer the following research question: To what extent do consultations enable the participation of a diverse set of stakeholders? And what explains the diversity of stakeholder mobilisation across a large set of consultations? While most research on EU agencies looks at agency autonomy, the establishment of agencies and how agencies relate to their political principals, few scholars have systematically investigated how agencies interact with stakeholders (Rittberger and Wonka 2011; Egeberg and Trondal 2017). Moreover, existing studies focus on only one or two policy domains, limiting generalisability (Borrás et al. 2007; Thiel 2014; Chalmers 2015). The crosssectional approach of this article allows for generalisation across policy domains, ranging from the regulation of chemicals to pharmaceuticals and aviation safety.

\footnotetext{
${ }^{1}$ For an overview of how the EU's regulatory policy process works, especially its consultation regime, we refer to the more general literature (Wonka and Rittberger 2010; Quittkat 2011; Rittberger and Wonka 2011; Van Ballaert 2017; Bunea 2017; Egeberg and Trondal 2017).
} 
To answer the research questions, we analyse a novel data set including 2,677 stakeholders participating in 358 public consultations organised by EU agencies. Our analyses lead to several conclusions. First, stakeholder participation in EU agency consultations is largely a matter of business representation, as most information agencies receive via these consultations comes from stakeholders representing regulated industries. Second, legal rules on stakeholder involvement have a conditional impact on the mobilisation of nonregulated interests. Third, despite the overall dominance of business interests, agencies have some leeway to design consultations in a way that nonregulated interests are more inclined to participate, for instance, by consulting at the early stage of the policy process.

\section{Explaining stakeholder diversity in public consultations}

To understand why regulators depend for their informational needs on the industries they are supposed to regulate, and how stakeholder diversity can mitigate capture, it is important to appreciate one rationale of government regulation, namely addressing market failures and negative externalities. ${ }^{2}$ To identify when and why externalities or market failures occur, and to design possible interventions and assess the potential consequences of these interventions, regulators need information about the activities of, and costs and benefits for, individuals and firms (Coglianese et al. 2004; Mattli and Woods 2009). Once regulators have identified market failures, negative externalities or product hazards, they need to consider regulatory remedies and gather information about the possible consequences of their policies. Such information not only includes compliance costs for companies and the extent to which new regulations would impact public health, but also information on potential unintended side effects (Coglianese et al. 2004). An EU agency official has described their motivation to involve stakeholders as follows:

They [the regulated sector] will ultimately be affected by the implementation of many of these rules and regulations. So, it helps us to understand the likely consequences, intended consequences or even the unintended consequences of the draft regulations that we produce. So it's really to give us, I suppose, in a way a real world perspective. (EU agency official, 7 May 2015) ${ }^{3}$

In short, stakeholder involvement is linked to legitimacy, as it could lead to higherquality policy outputs and may improve accountability (Borrás et al. 2007). First, stakeholder participation is expected to lead to better outputs, as the insights and information stakeholders supply stimulate deliberation and improve the problem-solving capacity of agencies. On the one hand, stakeholders provide

\footnotetext{
${ }^{2}$ The reasons for regulatory intervention are manifold and include policies addressing positive and negative externalities, price stabilisation, preventing monopolies, coping with asymmetric information and so on. These rationales are not all equally benign in terms of addressing market failures. For instance, some economists have argued that regulatory interventions largely benefit specific industries and aim to "retard the rate of growth" of competing industries, and therefore, in their view, market imperfections do not underpin regulatory interventions (Stigler 1971; Peltzman 1976).

${ }^{3}$ The quotes in this article are from interviews with stakeholder relation officers from EU regulatory agencies, conducted by the authors in 2015-2016 (Arras and Braun 2018). Respondents were guaranteed full anonymity.
} 
technical and scientific information which may lead to better, expertise-based decisions. On the other hand, as stakeholders press for transparency from the side of the agencies, the deliberative qualities of agencies are expected to increase as well (Agné et al. 2015). Second, involving stakeholders can raise accountability, as a large and diverse set of stakeholders may monitor the agencies and bring new information into the public debate. This is what principal agency theorists have labelled as "fire alarm oversight"; civil society can push agencies to adopt more transparent and open policymaking procedures and to publicise information on their decisions (McCubbins and Schwartz 1984; Kelemen 2002; Arras and Braun 2018). The disclosure of such information makes it easier for both principals and the public to hold agencies accountable.

Although the reasons for regulatory interventions are multifarious, often the costs of regulations are concentrated among a selected set of companies in a particular field, while the benefits are diffusely spread among all citizens or a broader range of industries. For instance, the regulatory costs of addressing the negative externalities of specific economic activities (e.g. pollution) are often borne by specific industries (e.g. the chemical industry), while the benefits are of a more diffuse nature (e.g. cleaner air). Therefore, regulated industries' need and readiness to develop expertise, lobby and participate in consultations are substantial. Organisations representing these industries also have an information advantage that stems from their acquaintanceship with companies that acquire expertise as a by-product of their everyday economic activities (Bouwen 2002; Barkow 2010; Pagliari and Young 2014). Moreover, these regulated industries have an incentive to provide policymakers with self-serving information (Coglianese et al. 2004; Mattli and Woods 2009). Hence, while the agencies' usage of information supplied by regulated industries may lead to more effective regulation and a smoother implementation process, it could lead to capture, namely policies systematically favouring regulated industries to the disadvantage of the general interest (Carpenter 2001, 2010; West and Raso 2013; Carpenter and Moss 2014; Kwak 2014). For instance, manufacturers gather information about the costs of producing a specific product, such as labour costs, but will focus less on the environmental burdens of their activities. Even if they are aware of environmental costs, they might be tempted to withhold this information (Coglianese et al. 2004). As Schlozman and Tierney have put it: "A policymaker who hears from only one side - or who hears much more from one side than the other - is likely to be persuaded by the arguments and information to which he or she is exposed" (1986, 165, cited in Furlong 1997, 329). This proposition also follows from resource dependence theory, which states that organisations are likely to be influenced by those who control the resources they need (Pfeffer and Salancik 1978).

For other stakeholders, such as consumers, or business interests that are not part of the regulated sector but might be indirectly affected by regulation, it is costlier to acquire sufficient expertise, and thus to participate in consultations (Broscheid and Coen 2007; Pagliari and Young 2016). This is especially the case for those stakeholders representing nonbusiness interests such as labour, consumer concerns and groups advocating on behalf of environmental causes. Many studies indeed demonstrate that business groups and citizens' groups are unequally endowed with political and technical resources. Furthermore, the former are better able to mobilise resources over a prolonged period of time, are more actively involved in public 
consultations and gain better access to policymakers (e.g. Eising 2007; Dür and Mateo 2016). Hence it is no surprise that most research demonstrates that regulators, albeit to varying degrees, are strongly lobbied by regulated industries (e.g. Yackee and Yackee 2006; West and Raso 2013; Yackee 2014a, 2014b; Rasmussen and Carroll 2014).

To prevent capture, it might be helpful for regulators to be exposed to information from different sources (Yackee and Yackee 2006; Braun 2012; Coglianese et al. 2004; Pagliari and Young 2016). A more balanced representation - involving both regulated industries and nonregulated interests - may mitigate information asymmetries and attenuate market power by countering the dominant position of regulated industries in regulatory governance (Coglianese 1997; Bernauer and Gampfer 2013; Damonte et al. 2014). First, while research on interest groups is often focused on conflict between business and nonbusiness interests, some recent research highlights the relevance of conflict between different business interests (Young and Pagliari 2017; Pagliari and Young 2016). For instance, while oil companies are less likely to provide policymakers with complete information about the environmental costs associated with their industry, renewable energy companies have a strong incentive to do so. A second source of information is citizen groups or NGOs, which represent public interests that are not directly related to professional activities, and advocate for policies that do not directly benefit their members or supporters (Dür and Mateo 2016; Pagliari and Young 2016). More specifically, compared to regulated industries, nonbusiness interests are more inclined and motivated to develop expertise on positive and negative externalities, which makes them relevant sources of alternative information. Environmental organisations, for instance, can inform regulators about the environmental damage caused by plastic production, which plastic producers themselves might be less inclined to do. Third, experts, such as doctors and lawyers, can provide regulators with alternative pieces of information (Dür and Mateo 2016). Regulating pharmaceuticals, for example, requires information about potential sideeffects. Doctors' associations are, compared to pharmaceutical companies, more likely to provide such information about specific products and will probably focus more on products' effectiveness when communicating with regulators.

Public consultations have been explicitly promoted as an instrument to foster the participation of a diverse set of stakeholders in regulatory policies, both in the EU and the US (e.g. Yackee and Yackee 2006; Moffitt 2010; Quittkat 2011; Quittkat and Kotzian 2011; Rasmussen and Carroll 2014; Bunea 2017). Characterised by a low threshold to participate (stakeholders can participate by submitting comments online, which requires less effort than face-to-face meetings with policymakers), and openness (consultations are usually open to anyone who wishes to participate), consultations have the potential to equalise access opportunities and encourage the participation of stakeholders other than regulated industries. Nonetheless, in the context of the EC consultations, several studies have indicated that business interests typically outnumber NGOs, trade unions and professional organisations (Quittkat 2011; Quittkat and Kotzian 2011; Klüver 2012; Rasmussen and Carroll 2014; Berkhout et al. 2018). These studies usually do not make a distinction between regulatees and other business interests. While the underlying logic of public consultations is to provide interested stakeholders the opportunity to voice feedback on proposed rules, several studies indicate that business interests systematically make up the largest share of commenters and are more successful in attaining their 
preferred outcomes (Furlong and Kerwin 2005; Yackee 2006, 2013; Yackee and Yackee 2006; Quittkat 2011; Quittkat and Kotzian 2011; West and Raso 2013; Rasmussen and Carroll 2014).

\section{Hypotheses}

This article analyses stakeholder diversity, more precisely, the extent to which stakeholders other than the regulated sector participate and provide information in public consultations organised by EU agencies. To begin, stakeholder participation can be seen as a function of the overall accessibility of a public consultation. More concretely, we argue that early-stage consultations, consultations phrased in layman's terms and closed-format consultations, demonstrate a higher level of accessibility, leading to more diversity.

EU agencies fulfil two important functions in the regulatory process, one during the development of regulations and another when regulations are implemented (Egeberg and Trondal 2017). At the start of the regulatory cycle, when the EC develops regulatory proposals, agencies have an advisory role. Agencies pool expertise within their policy field and can play a crucial role in the early stage of the regulatory process by feeding information to the European legislative institutions. The agendasetting role of agencies can be used by stakeholders to push their preferences into regulatory proposals. An example is a consultation organised by the European Insurance and Occupational Pensions Authority (EIOPA) in 2013 on a possible EU single market for personal pension products, after the EC asked EIOPA to deliver technical advice on the prudential regulations and consumer protection measures that would be needed to create such a single market (EIOPA 2013).

Second, EU agencies are key players in the implementation phase of regulations, in other words, the final stage of the regulatory cycle. They draft implementing rules which specify the application of a regulation, an important task since EU regulations are often rather broadly formulated as a result of compromises between the EU member states (Coen and Thatcher 2008). The Body of European Regulators for Electronic Communications (BEREC), for instance, consulted stakeholders on draft guidelines for the application of the Roaming Regulation (BEREC 2013). Countervailing forces to the regulatees are less likely to mobilise in the implementation phase, since the discussion at that point revolves around filling in the highly technical details - which can still have important consequences for the regulatees but the essence of the regulation, which has been adopted in the legislative phase, will no longer change drastically. As the scope of the conflict narrows towards the implementation phase of a regulation, bias towards regulated industries will increase and stakeholder diversity will decrease (Schattschneider 1960; Yackee and Yackee 2006; West and Raso 2013; Berkhout et al. 2018).

Another factor likely to affect whether stakeholders other than the regulatees mobilise is the technical complexity of the issue at hand. "A highly complex issue is one that raises factual questions that cannot be answered by generalists or laypersons" (Gormley 1986, 598, cited in Yackee 2006, 132). Complex issues require more expertise and knowledge from stakeholders who want to take part in consultations, and therefore, the more complex a topic, the higher the cost to participate. This makes it problematic for nonregulatees, especially nonbusiness 
interests, to express their preferences (Yackee 2006; West and Raso 2013; Rasmussen and Carroll 2014; Young and Pagliari 2017; Pagliari and Young 2016; Røed and Wøien Hansen 2018). Moreover, especially with regard to highly complex policies, agencies depend on expertise from regulated industries, increasing the likelihood of capture (McCarty 2014). Based on previous studies on stakeholder mobilisation controlled for complexity as an inherent and fixed characteristic of the issue at hand (Yackee and Yackee 2006; Klüver 2012; Pagliari and Young 2016), we hypothesise that policymakers have some leeway in how to communicate about the issues under consultation. To increase diversity in the set of stakeholders that participate, agencies can choose to put some effort into communicating in layman's terms. One official has described an agency's efforts to reach stakeholders other than the regulatees as follows:

It's very hard to go beyond the stakeholders that actually understand what we are doing in this specific field. We are discussing very much within the agency, how to reach further. [...] We try to explain this, for example, through citizens' summaries on our website, explaining in more layman's terms what the impact of some of our decisions or proposals are. But it's not that simple, simply because we are away from the people who feel the benefits of this. (EU agency official, 18 March 2015)

Third, the format of consultations, which agencies are free to choose, is expected to affect who participates. In particular, one consultation characteristic will impact nonregulatees' incentive to mobilise, namely the response format, or how stakeholders are asked to comment (Quittkat 2011; Pagliari and Young 2016). Providing valuable information in an open format requires more resources in terms of staff and expertise than ticking boxes in a standardised questionnaire. This implies a trade-off: an open format, which enables the provision of high-quality and detailed information, will lead to lower participation rates by groups with fewer resources, usually nonregulatees.

In summary, we propose three hypotheses in relation to the consultations:

(H1): Early-stage consultations attract more nonregulated interests than latestage consultations.

(H2): Consultations phrased to a greater extent in layman's terms attract more nonregulated interests than other consultations.

(H3): Consultations with a standardised response format attract more nonregulated interests than consultations with an open-response format.

Next, we test whether contextual factors at the agency level - more precisely, the agency's age, institutional rules and the composition of the agency's advisory committees - affect nonstakeholder participation. First, principals (i.e. the legislators who establish agencies) may develop norms expecting agencies to provide access to nonregulated interests such as consumer or patient organisations. To perform legislative oversight, legislators aim for a certain balance of interests by institutionalising the participation of organised interests representing interests other than regulated industries (McCubbins and Schwartz 1984; Kelemen 2002). For instance, previous research on EU agencies has indicated that most EU agency advisory 
committees are legally required by the founding regulation to involve stakeholders other than the regulated sector, and several EU agencies' legal statutes also contain requirements regarding such involvement (Arras and Braun 2018; Pérez Durán 2018). Agencies that have such legal requirements will invest more in contacts with nonregulated interests. As they are expected to reach out to nonregulated interests or at least keep them informed, they therefore also attract a more diverse set of consultation participants.

Second, several agencies have established advisory committees in which stakeholders are represented. These committees are permanent bodies providing agencies with advice on various regulatory issues. Agencies have some leeway in how these committees are established. Some committees are more diverse - for instance in terms of the nonbusiness interests involved - compared to other committees. Many studies have demonstrated that mobilisation in one arena spills over into mobilisation in other arenas (Quittkat and Kotzian 2011; Binderkrantz et al. 2015). This leads us to hypothesise that agencies establishing consultative bodies with less diversity will exhibit less diversity among consultation participants. ${ }^{4}$

Third, agency age indicates an agency's organisational development. Traditionally, it has been argued that over time agencies become more dependent on the regulated sector, so participation by nonregulated interests is expected to be less for more established and older agencies (Maggetti 2007; Kwak 2014; Novak 2014). However, EU agencies are still relatively young (between 7 and 15 years), which makes it impossible to estimate their long-term institutional development. Therefore, we believe that in the short time span of these agencies' existence, another mechanism is at work. More precisely, as regulated industries have more resources (see above), it is plausible to presume that they mobilise faster than nonregulated interests, implying that regulated industries mostly address recently established agencies (see also Hanegraaff 2015). After the short period of their initial establishment, agencies will actively seek more diverse stakeholder participation, and nonregulated interests will overcome their collective action problems, resulting in greater stakeholder diversity among somewhat older agencies.

In summary, we propose the following hypotheses:

(H4): Agencies that are legally required to promote broad stakeholder involvement attract more nonregulated interests.

(H5): If an agency advisory body demonstrates a high level of diversity, more nonregulated interests mobilise in consultations.

(H6): Older agencies attract more nonregulated interests.

\section{Research design}

Of all the EU regulatory agencies operational on 1 January 2015 ( $N=16)$, those which organise public consultations were selected, resulting in 10 agencies being

\footnotetext{
${ }^{4}$ However, the opposite might also happen, namely with more diverse consultative bodies, stakeholders are less likely to participate in public consultations (because they might enjoy access as members of advisory bodies).
} 
Table 1. EU regulatory agencies, consultation organised (n), and whether agency is legally required to consult nonstate stakeholders

\begin{tabular}{lcc}
\hline Agency & $\begin{array}{c}\text { Legally } \\
\text { Required }\end{array}$ & $\begin{array}{c}\text { Total } \\
\text { Consultations }\end{array}$ \\
\hline ESMA & Yes & 32 \\
\hline EBA & Yes & 57 \\
\hline EIOPA & Yes & 20 \\
\hline Joint consultation organised & Yes & 9 \\
by ESMA, EBA and EIPO & & 9 \\
\hline EFSA & Yes & 72 \\
\hline EMA & Yes & 63 \\
\hline ERA & Yes & 3 \\
\hline ACER & No & 10 \\
\hline EASA & No & 39 \\
\hline ECHA & No & 26 \\
BEREC & No & 27 \\
\hline Total & & 358 \\
\hline
\end{tabular}

included in the analysis (Table 1). However, there was considerable variation in data accessibility. The websites of the three financial agencies (the European Banking Authority, the EIOPA, and the European Securities and Markets Authority), the Agency for the Cooperation of Energy Regulators (ACER) and the BEREC provide sections listing past consultations, an overview of the participants per consultation and the response documents. These five agencies are more recently established agencies, possibly indicating a trend towards more transparency with respect to stakeholder involvement. The European Food Safety Authority (EFSA) website lists all past consultations in a separate section, but the overview of participants and the responses are published elsewhere, according to the topic of the consultation. For the European Aviation Safety Authority (EASA), the European Chemicals Agency (ECHA), the European Union Agency for Railways (ERA) and the European Medicines Agency (EMA), we were unable to find any information regarding past consultations on the agencies' websites. After a document request, these agencies provided us with lists of consultations and participants (or detailed instructions on where to find the documents; sometimes this information was spread across different subsections of the websites). In total, we identified 413 consultations organised in 2013 and 2014. For 15 consultations, we could only find a general consultation call, but no consultation text and/or list of consultees. In 40 instances, publicly available documents did not list consultation participants, and in several of these cases, the agency website reported that no one had responded to the consultation call. Hence, we could code 358 consultations for three types of evidence: information about the stakeholders, agency characteristics and consultation features. Table 2 gives a descriptive overview of dependent, independent and control variables. 
Table 2. Overview of dependent, independent and control variables

\begin{tabular}{|c|c|c|c|c|}
\hline Variable & Mean & SD & Min. & Max. \\
\hline \multicolumn{5}{|l|}{ Dependent variables } \\
\hline $\mathrm{HHI}$ consultations & 0.58 & 0.23 & 0.21 & 1 \\
\hline Proportion nonregulated interests & 0.27 & 0.24 & 0 & 1 \\
\hline Proportion other business interests & 0.10 & 0.14 & 0 & 1 \\
\hline Proportion nonbusiness interests & 0.04 & 0.10 & 0 & 1 \\
\hline Proportion experts & 0.13 & 0.18 & 0 & 1 \\
\hline \multicolumn{5}{|l|}{ Independent variables } \\
\hline Consultation type $(1=$ implementation, $2=$ policy advice $)$ & 1.22 & 0.42 & 1 & 2 \\
\hline Complexity (four categories) & 2.55 & 1.15 & 1 & 4 \\
\hline Format $(1=$ open, $2=$ closed $)$ & 1.34 & 0.47 & 1 & 2 \\
\hline Legal requirements $(0=$ no, $1=$ yes $)$ & 0.72 & 0.45 & 0 & 1 \\
\hline $\mathrm{HHI}$ advisory board & 0.42 & 0.16 & 0.26 & 0.67 \\
\hline Agency age & 10.98 & 3.45 & 7 & 15 \\
\hline \multicolumn{5}{|l|}{ Control variables } \\
\hline Duration (days) & 79.86 & 48.39 & 7 & 458.00 \\
\hline Number consultation participants (logged) & 2.40 & 1.04 & 0 & 5.48 \\
\hline
\end{tabular}

In total, we identified 2,677 distinct consultation participants. Consultation participation is highly skewed, with many participants taking part in just one consultation (65\% or 1,729 actors participated in only one consultation), and a very small set of highly active stakeholders (4\% or 115 actors had been involved in 10 or more consultations). Each identified stakeholder was coded based on information available on its website. The coding scheme was developed on the basis of an existing codebook developed for various other research projects (see INTEREURO project, www.intereuro.eu). In case no or insufficient information could be obtained from the organisation's website, we referred to other sources such as Wikipedia, LinkedIn and the EU's Transparency Register, and, in several instances, we could obtain relevant information from position papers that had been submitted during the consultations. ${ }^{5}$ In addition to the authors, three student coders took part in the coding process. To improve validity and reliability, all codes were crosschecked by different coders, and in cases of doubt, we organised meetings among the coders in order to establish a final code.

The key variable stakeholder type consists of five distinct categories. Our main point of reference is regulated interests, representing industries that are directly and profoundly targeted by agency regulations. There are four other stakeholder types that are distinct from these regulated businesses. To begin, there are nonregulated

\footnotetext{
${ }^{5}$ Not all actors could be identified or coded. To begin, there was a small set of consultees ( 28 companies, one NGO, one public authority and one trade association involved in ECHA consultations) that submitted anonymised reports. Also, 14 actors could not be identified and/or coded, either because they did not have a website or we could not find relevant information from other sources.
} 
business interests, which concern industries that are not directly regulated and/or businesses for which the regulated sector does not constitute its core economic activities, for instance, businesses depending on regulated industries (see below). In order to facilitate our work, we coded each stakeholder on the basis of the United Nations International Standard Industrial Classification of All Economic Activities (ISIC), assigning each business actor to an economic sector (United Nations 2008; see also Young and Pagliari 2017). First, for each agency, we checked all ISIC codes falling within the scope of the sector regulated by that agency. For the ECHA, for instance, these are all codes covering the manufacturing of chemicals and chemical products. Second, again for each agency, all business interests were coded as either from a regulated sector (e.g. organisations representing chemicals company in the case of the ECHA) or from a nonregulated sector (e.g. car manufacturer interests in the case of the ECHA). Third, based on information provided on the organisations' website, we crosschecked the final coding for each stakeholder.

In addition to these business interests, we identified nonbusiness interests, which include organisational entities that do not represent companies, but which claim to speak on behalf of some general citizens' interest. These concern consumer interests, specific causes such as human rights, animal rights, environmental or health concerns, labour rights or other general causes. More specifically, within this category, we find labour unions as well as a diverse range of NGOs. It should be noted that, for the purpose of this article, modelling the involvement of nonbusiness interests is highly relevant because this actor type, especially - compared to experts, other business interests and public authorities - lacks resources as well as expertise. We also identified a set of consultees we labelled "experts." They are representatives of professional associations, institutions such as hospitals or research institutes, and various national expert bodies. Finally, several EU-level agencies grew out of EU-wide regulatory networks consisting of national-level regulators. National governments are key decisionmakers in EU legislative processes and often national regulators take an active part in implementing EU regulations (Egeberg and Trondal 2011, 2017; Quittkat 2011; Bunea and Thomson 2015). Hence, we established a separate category for public authorities. As Table 4 illustrates, national regulatory authorities mobilise in large numbers on the aviation sector and aviation safety (EASA) and medicine regulation (EMA).

Next, we have three variables at the agency level. The first two - agency age and legal provisions - were coded on the basis of official documents. With respect to legal provisions, we read the agencies' legal statutes and looked at whether agencies are explicitly expected to consult with stakeholders other than the regulated sector (for instance, consumer groups, environmental groups or patient organisations). These agencies are supposed to invest more in contacts with stakeholders outside the regulated sector by actively reaching out to them, thereby also attracting a more diverse set of consultation participants. To determine the diversity of the advisory committee, we coded all committee members in the same way that we coded all other stakeholders. For both the advisory committees and the public consultation participants, we calculated the Herfindahl-Hirschman index (HHI) as a measure of diversity, in other words, to what extent stakeholders are concentrated in one or more group types (Rasmussen and Carroll 2014; Chalmers 2015). The HHI is calculated as the sum of the squared proportions of stakeholders belonging to each 
of the group type categories. The HHI ranges from 1 (minimal diversity, namely all consultation participants belong to the same group type) to $1 / \mathrm{N}$, with $\mathrm{N}$ equal to the number of groups (maximal diversity, namely each group type participates to an equal degree). For our data set, the range of the HHI is the interval $[0.20,1]$.

Finally, the characteristics of the 358 public consultations were coded after reading the consultation call, that is, a short text describing what the consultation is about, and reading the attached more elaborate consultation articles or draft documents. The consultation type was coded into two main categories (see Pagliari and Young 2016). First, implementation cases take place at the end of the regulatory process, and the issue at hand deals with executing existing EU legislation via implementing decisions. Second, some consultations seek general policy advice that is not directly related to the implementation of existing legislation. This may entail advice on future legislative proposals, feedback on the agency's long-term strategy (such as a future multi-annual framework), or recommendations on the internal functioning of the agency (for instance, on the agency's consultation practices).

Policy complexity is an intricate concept, both in terms of conceptualisation and operationalisation. Most consultation calls consist of, on the one hand, a short text announcing or preceding the consultation (called an "announcement," "executive summary" or "paper overview"), and, on the other hand, a more elaborate article discussing the topic in more detail. For all these documents we coded the level of complexity based on a four-level scale ("very simple," "simple," "complex" and "very complex") (see Yackee 2006; Yackee and Yackee 2006; Pagliari and Young 2016). A sample of 40 consultations were double-coded by two independent coders to test whether the scale works well; the coding of the announcement resulted in a high degree of reliability (Krippendorff $s=0.87$ ), while establishing a reliable measure on the basis of the more extensive articles proved to be much more difficult (Krippendorff's $\alpha=0.62$ ). The lower reliability score for the consultation articles is not entirely surprising, because such documents are more dense and often combine highly technical insights with some general information, making it more difficult to assess complexity in a reliable way.

Importantly, both measures do not cover the inherent or actual complexity of policy issues, but rather the complexity with which an agency presented the policy issue and, especially, how this might be viewed by a potential consultee. On the one hand, complexity has a subjective component in the sense that what one individual experiences as complex might be relatively simple for someone else. On the other hand, how agencies portray a specific issue cannot be entirely separated from the objective nature of the issue, so that we cannot rule out that some variation might be driven by intrinsic issue complexity. In essence, our measure seeks to separate consultations that are presented as highly specialised and technical from those where a lay person could decipher what a particular consultation is about. It is worth taking a closer look at how these two measures correlate. To begin, as Table 3 illustrates, many consultations were coded as "complex" or "very complex". This was especially the case for consultation articles (78\% are "complex" or "very complex"), but much less so for short announcements ( $51 \%$ are "complex" or "very complex"). Also, both measures are considerably correlated, implying that they potentially measure the same underlying construct $\left(\chi^{2}=228.30, p<0.0001, d f=9\right.$, Spearman's $\left.\rho=0.69\right)$. Yet, the substantial number of cases in the top right of the diagonal (30\%) suggests 
Table 3. Comparing complexity of consultation article with complexity announcement

\begin{tabular}{lccccc}
\hline & \multicolumn{5}{c}{ Complexity Consultation Article } \\
\hline Complexity Announcement & Very Simple & Simple & Complex & Very Complex & Total \\
\hline Very simple & 20 & 27 & 38 & 3 & 88 \\
\hline Simple & $6 \%$ & $8 \%$ & $11 \%$ & $1 \%$ & $25 \%$ \\
\hline & 0 & 19 & 47 & 16 & 82 \\
\hline Complex & - & $5 \%$ & $13 \%$ & $5 \%$ & $23 \%$ \\
\hline & 3 & 2 & 42 & 32 & 79 \\
\hline Very complex & $1 \%$ & $1 \%$ & $12 \%$ & $9 \%$ & $22 \%$ \\
& 1 & 5 & 3 & 94 & 103 \\
\hline Total & $0 \%$ & $1 \%$ & $1 \%$ & $27 \%$ & $29 \%$ \\
\hline & 24 & 53 & 130 & 145 & 352 \\
\hline
\end{tabular}

that in drafting consultation calls, agency officials produce announcements that are perceived as less complex compared to the corresponding consultation articles.

As the coding of the shorter announcement resulted in a more reliable measure, we decided to use this as our primary independent variable. However, in a small number of cases $(n=6)$, we could not find a consultation announcement (or general overview, executive summary). In these cases, potential consultees had to depend on the, generally more complex, consultation article when deciding on whether or not to take part in the consultation. Therefore, for the cases without a short announcement, we imputed the complexity measures of the consultation articles.

Finally, the consultation format indicates how stakeholders are asked to respond to the consultation. A consultation can be open or standardised. An open format means that the agency presents a certain issue or a draft document and asks stakeholders to provide feedback without asking specific questions. In consultations with a standardised response format, stakeholders are asked to provide answers to specific questions.

Our models include two control variables. First, we controlled for the duration of the consultation, measured as the number of days between the published call and the deadline to comment (Quittkat 2011; Røed and Wøien Hansen 2018). Formulating and drafting a position takes time, so the longer the consultation is open, the more stakeholders are expected to participate. Second, we controlled for the number of stakeholders (logged count variable) that present themselves in each consultation, as one might presume that the diversity of consultees, or the chance that nonregulated interests will present themselves, increases as more stakeholders take part in the consultation (Rasmussen and Carroll 2014; Bunea and Thomson 2015). ${ }^{6}$

\footnotetext{
${ }^{6}$ Given the fact that we included consultations organised by nine different agencies, there is quite some diversity. One obvious question concerns the varying salience of the involved issues and whether we should control for this, because much political mobilisation is driven by political salience. However, with respect to salience, nearly all issues in the database are characterised by low levels of public salience. We checked the
} 
Table 4. Share and diversity of consultation participations by agency (percentages, average HHI consultees and $\mathrm{HHI}$ committee members)

\begin{tabular}{|c|c|c|c|c|c|c|c|c|}
\hline & $N$ & $\begin{array}{l}\text { Regulated } \\
\text { Business }\end{array}$ & $\begin{array}{l}\text { Other } \\
\text { Business }\end{array}$ & Nonbusiness & Experts & $\begin{array}{c}\text { Public } \\
\text { Authorities }\end{array}$ & $\begin{array}{c}\mathrm{HHI} \\
\text { Consultation }\end{array}$ & $\begin{array}{c}\mathrm{HHI} \\
\text { Committee }\end{array}$ \\
\hline $\begin{array}{l}\text { EBA } \\
\text { (banking) }\end{array}$ & 601 & 86.2 & 8.8 & 1.7 & 1.7 & 1.7 & 0.80 & 0.26 \\
\hline $\begin{array}{l}\text { ESMA } \\
\text { (securities) }\end{array}$ & 1306 & 68.6 & 18.8 & 2.4 & 7.1 & 3.1 & 0.65 & 0.58 \\
\hline $\begin{array}{l}\text { EIOPA } \\
\text { (insurance) }\end{array}$ & 439 & 61.3 & 17.3 & 5.0 & 12.8 & 3.6 & 0.46 & 0.28 \\
\hline $\begin{array}{l}\text { Joint EBA, } \\
\text { ESMA and } \\
\text { EIOPA }\end{array}$ & 252 & 74.6 & 15.5 & 2.4 & 6.8 & 2.8 & 0.66 & - \\
\hline $\begin{array}{l}\text { ACER } \\
\text { (energy) }\end{array}$ & 390 & 85.9 & 10.0 & 0.5 & 0.5 & 3.1 & 0.77 & 0.58 \\
\hline $\begin{array}{l}\text { BEREC } \\
\text { (telecom) }\end{array}$ & 440 & 77.1 & 12.1 & 7.7 & 0.7 & 2.5 & 0.71 & - \\
\hline $\begin{array}{l}\text { EMA } \\
\text { (medicines) }\end{array}$ & 431 & 54.3 & 6.5 & 2.6 & 23.7 & 13.0 & 0.62 & 0.27 \\
\hline $\begin{array}{l}\text { EASA } \\
\text { (aviation) }\end{array}$ & 818 & 49.8 & 3.2 & 6.9 & 3.2 & 31.9 & 0.44 & 0.67 \\
\hline $\begin{array}{l}\text { ECHA } \\
\text { (chemicals) }\end{array}$ & 449 & 32.7 & 46.1 & 2.7 & 6.0 & 12.5 & 0.47 & 0.30 \\
\hline $\begin{array}{l}\text { ERA } \\
\text { (railways) }\end{array}$ & 22 & 36.4 & 4.5 & 13.6 & 0.0 & 45.5 & 0.45 & 0.46 \\
\hline $\begin{array}{l}\text { EFSA } \\
\text { (food) }\end{array}$ & 1294 & 29.2 & 11.9 & 11.1 & 23.9 & 24.0 & 0.41 & 0.53 \\
\hline $\mathrm{N}$ & 6442 & 3719 & 921 & 325 & 687 & 790 & & \\
\hline Percentage & & 57.7 & 14.3 & 5.0 & 10.7 & 12.3 & & \\
\hline
\end{tabular}

\section{Analysis}

A descriptive examination of who participates in EU agency consultations (Table 4) reveals considerable variation across agencies and stakeholder types. Some agencies exhibit very high concentrations of certain stakeholder types, largely due to the strong prevalence of regulated businesses. Stakeholders mobilising in the energy (ACER), telecom (BEREC) and banking (EBA) sectors come almost exclusively from the regulated sector, representing 86,77 and $86 \%$, respectively, of all consultation participants. Regulated business interests also dominate consultations on the regulation of securities (ESMA), insurance and pensions (EIOPA), representing 69

public or media salience for a small set of topics (20), more precisely those where we observed the greatest number of consultees. Based on the fact that search engines such as Google Trends and EurActiv produced no of just a few hits, we could safely conclude that public salience is rather low. However, a key variable, namely the number of stakeholders taking part in the public consultations, can be seen as a proxy for actor salience, namely the extent to which an issue is important for individual stakeholders (Beyers et al. 2018). It should be noted that this measure (the number of participants in a consultation), as most other political attention measures, has a highly skewed distribution. 
and $61 \%$, respectively, of all consultation participants. A more diverse set of stakeholders is mobilised in the regulation of pharmaceuticals (EMA) and aviation safety (EASA), but still about half of all participants represent regulated industries. The mobilisation of nonregulated stakeholders is strongest with respect to chemicals (ECHA), railways (ERA) and food safety (EFSA).

However, one should (always) be careful about drawing strong conclusions. In several instances, the set of regulated businesses is quite diverse, and sometimes it was difficult to establish the boundaries between regulated and nonregulated businesses. For instance, in the case of the ACER, the set of regulated businesses comprises a wide array of stakeholders, including local energy suppliers, public and private enterprises, businesses specialising in renewable energy, as well as producers relying on fossil energy sources. Another example is the ECHA, where we find many other business interests. This is largely because manufacturing companies in many sectors - ranging from electronics to the automotive industry - depend for a small but significant part of their activities on chemical products. Finally, in some fields - for example, the EFSA and the EMA - the substantial number of experts who do not represent companies or business interests may somewhat attenuate the prevalence of regulated businesses. Because their professional activities are situated in the regulated sector, these actors are highly knowledgeable about the potential consequences of regulatory activities. However, sometimes these professional activities could create conflicts of interests, for instance, because the experts depend on regulated companies for research grants (Corporate European Observatory 2013).

Nonetheless, despite these cautionary notes, the dominance of the regulated industries is substantial. This can also be illustrated by comparing the number of consultations where regulated industries did not attend with the number of consultations where other stakeholder types did not attend. Only 7\% of the consultations are characterised by the absence of regulated industries, while this figure is $44 \%$ for experts, $44 \%$ for other business interests, $38 \%$ for public authorities and $70 \%$ for nonbusiness interests. Overall, nonbusiness interests - such as consumer NGOs, environmental NGOs and labour unions - are poorly represented in EU agency consultations. These actors constitute about $5 \%$ of the participating stakeholders. Only the BEREC, the ERA, the EASA and the ESA attract a considerable number of nonbusiness interests (respectively, $8,14,7$ and $11 \%$ of all participants), mostly environmental and consumer organisations.

Do these results differ from other venues, for instance, within the EU? Although it goes beyond the scope of this article to provide a systematic comparative analysis, the available evidence suggests that nonregulated interests are especially poorly represented in agency public consultations. One way to contextualise this observation is to compare the representation of nonregulated interests in consultations with the composition of the advisory committees that $\mathrm{EU}$ agencies have established. The committee HHIs indicate that the diversity in these advisory committees (Table 3), despite the strong presence of regulated interests in these bodies, is substantially higher (or similar) compared to the diversity of stakeholders in public consultations. Interestingly, while the number of participants in advisory committees is limited, these bodies realise a more balanced set of represented interests (Quittkat and Kotzian 2011, 412). Moreover, while on average only 5\% of the consultees in agency consultations represent nonbusiness interests, this figure is $12 \%$ in 
advisory committees. There is ample research analysing how private interests interact with the EC, for instance via open consultations organised by the EC. Compared to the results reported here, most of these studies report higher representations of nonbusiness and citizen interests. Depending on the sample method, the study design and the policy field, and despite the strong prevalence of business groups, the share of citizen groups and nonbusiness interests in the mobilised interest group population typically ranges between 10 and 30\% (e.g. Wonka et al. 2010; Quittkat 2011; Quittkat and Kotzian 2011; Rasmussen and Carroll 2014; Rasmussen and Gross 2015; Berkhout et al. 2018).

Table 4 suggests that the diversity of consultation participants relates to the agency organising the consultation. Yet, this assertion does not clarify whether agency features or consultation characteristics account for this diversity. In order to analyse the diversity across consultations, we tested regression models with the consultation $\mathrm{HHI}$ and the proportion of nonregulated interests - the combination of other business interests, nonbusiness interests and experts - as dependent variables (Table 5, Parts I and II). One drawback of the HHI and the proportion of nonregulated interests is that these measures do not clarify in which actor type - experts, nonbusiness interests or other business interests - observations are concentrated. For instance, is greater diversity the result of experts taking part in the consultations or the increased mobilisation of civil society groups? As an additional robustness check, we tested three separate models with the proportions of nonregulated business interests, nonbusiness interests and experts as dependent variables (Table 5, Part III). Because of the proportional nature of the dependent variable, we used a fractional logit model (Papke and Wooldridge 1996). As participation patterns in one consultation may affect what happens in other consultations, we cannot presume that each consultation is an entirely independent observation, which could lead to biased standard errors and increase the risk of type I errors. Therefore, we estimated robust standard errors to account for potential dependencies. Furthermore, consultations are nested within one of the nine agencies, resulting in these consultations being similar, for instance, in terms of some unobserved variable such as actual policy complexity. ${ }^{7}$ In order to accommodate the multi-level structure of the data, we estimated a random intercept for the agency level.

Looking at the control variables, consultation duration has no significant effect on nonregulated stakeholder mobilisation or diversity. Controlling for the total number of mobilised interests confirms that, on average, a high mobilisation density corresponds to a more diverse set of consultation participants (a lower HHI) and more nonregulated interests, especially other business and nonbusiness interests (not experts).

The results are less straightforward when it comes to consultation-related factors. For instance, consultation format has no effect on the HHI or the proportion of nonregulated interests. Although nonregulated interests are more active in

\footnotetext{
${ }^{7}$ The BEREC does not have an advisory committee, and therefore, this agency was not included in the regression analysis. Although the data set has a multi-level structure, dependencies, measured by the intra-class correlation (ICC), are different for the different dependent variables (ICC for $\mathrm{HHI}=0.36$, non-regulated interests $=0.23$, other business interests $=0.17$, non-business interests $=0.07$ and experts $=0.23$ ).
} 
Table 5. Explaining $\mathrm{HHI}$ consultations and proportion nonregulated interests

\begin{tabular}{|c|c|c|c|c|c|c|c|}
\hline \multirow[b]{2}{*}{ Fixed part } & \multicolumn{2}{|c|}{ Part I: Noninteractive } & \multicolumn{2}{|c|}{ Part II: Interactive } & \multicolumn{3}{|c|}{$\begin{array}{l}\text { Part III: Estimating Proportion } \\
\text { Stakeholder Types }\end{array}$} \\
\hline & $\mathrm{HHI}$ & $\begin{array}{l}\text { Nonregulated } \\
\text { Interests }\end{array}$ & $\mathrm{HHI}$ & $\begin{array}{l}\text { Nonregulated } \\
\text { Interests }\end{array}$ & $\begin{array}{c}\text { Other } \\
\text { Business }\end{array}$ & Nonbusiness & Experts \\
\hline \multirow[t]{2}{*}{ Intercept } & 2.57 & -1.80 & 2.81 & -1.02 & 0.10 & -9.24 & -6.50 \\
\hline & $(0.75)^{*}$ & $(0.85)$ & $(0.22)^{\star \star}$ & $(0.13)^{\star \star}$ & $(0.43)$ & $(0.51)^{\star \star}$ & $(0.29)^{\star *}$ \\
\hline \multicolumn{8}{|l|}{ Consultation } \\
\hline \multirow[t]{2}{*}{ Type advice (implementation = ref) } & -0.01 & 0.34 & -0.01 & 0.35 & -0.19 & 0.59 & 0.37 \\
\hline & $(0.13)$ & $(0.13)^{*}$ & $(0.11)$ & $(0.12)^{\star \star}$ & $(0.13)$ & $(0.18)^{\star \star}$ & $(0.11)^{\star \star}$ \\
\hline \multicolumn{8}{|l|}{ Complexity (very simple $=$ ref) } \\
\hline \multirow[t]{2}{*}{ Simple } & -0.06 & -0.02 & -0.02 & 0.03 & 0.28 & -0.49 & -0.03 \\
\hline & $(0.14)$ & $(0.13)$ & $(0.15)$ & $(0.14)$ & $(0.18)$ & $(0.34)$ & $(0.12)$ \\
\hline \multirow[t]{2}{*}{ Complex } & 0.01 & -0.20 & 0.07 & -0.15 & -0.16 & -0.68 & 0.00 \\
\hline & $(0.13)$ & $(0.20)$ & $(0.13)$ & $(0.22)$ & $(0.27)$ & $(0.59)$ & $(0.18)$ \\
\hline \multirow[t]{2}{*}{ Very complex } & 0.03 & -0.17 & 0.19 & -0.19 & -0.14 & -1.33 & 0.07 \\
\hline & $(0.15)$ & $(0.13)$ & $(0.13)$ & $(0.11)$ & $(0.15)$ & $(0.53)^{*}$ & $(0.13)$ \\
\hline \multirow[t]{2}{*}{ Format closed (open $=$ ref) } & -0.20 & 0.23 & -0.19 & 0.36 & 0.34 & -0.22 & 0.29 \\
\hline & $(0.27)$ & $(0.24)$ & $(0.27)$ & $(0.24)$ & $(0.32)$ & $(0.29)$ & $(0.17)$ \\
\hline \multicolumn{8}{|l|}{ Contextual } \\
\hline \multirow[t]{2}{*}{ Legal requirements $(\mathrm{No}=$ ref) } & 0.01 & 0.11 & -0.25 & -1.70 & -2.94 & 4.21 & 2.63 \\
\hline & $(0.27)$ & $(0.42)$ & $(0.72)$ & $(0.71)$ & $(0.36)^{\star \star \star}$ & $(1.71)^{\star}$ & $(1.35)$ \\
\hline \multirow[t]{2}{*}{ HHI advisory board } & 0.94 & -2.39 & 3.78 & -6.33 & -6.43 & -8.76 & -9.31 \\
\hline & $(0.61)$ & $(1.41)$ & $(0.38)^{\star \star *}$ & $(0.35)^{\star \star \star}$ & $(0.67)^{\star \star \star}$ & $(1.46)^{\star \star \star}$ & $(0.34)^{\star \star \star}$ \\
\hline Agency age (years) & -0.14 & 0.10 & -0.29 & 0.18 & -0.04 & 0.82 & 0.67 \\
\hline
\end{tabular}


Table 5. (Continued)

\begin{tabular}{|c|c|c|c|c|c|c|c|}
\hline \multirow[t]{2}{*}{ Legal*agency age } & & & 0.18 & -0.09 & -0.04 & -0.67 & -0.51 \\
\hline & & & $(0.05)^{\star \star}$ & $(0.05)^{\star}$ & $(0.05)$ & $(0.13)^{\star \star \star}$ & $(0.07)^{\star \star \star}$ \\
\hline \multicolumn{8}{|l|}{ Control } \\
\hline Duration & -0.00 & -0.00 & -0.00 & 0.00 & -0.00 & -0.00 & 0.00 \\
\hline \multirow[t]{2}{*}{ Mobilisation density (logged) } & -0.41 & 0.22 & -0.40 & 0.24 & 0.49 & 0.33 & -0.08 \\
\hline & $(0.08)^{\star \star \star}$ & $(0.05)^{\star \star \star}$ & $(0.08)^{\star \star \star}$ & $(0.06)^{\star \star \star}$ & $(0.16)^{\star \star}$ & $(0.10)^{\star \star}$ & $(0.11)$ \\
\hline & $(0.23)$ & $(0.35)$ & $(0.33)$ & - & - & - & $(0.91)$ \\
\hline$-2 \mathrm{LL}$ & $1,144.67$ & $1,244.85$ & $1,144.26$ & $1,243.68$ & $1,528.94$ & $1,838.05$ & $1,454.68$ \\
\hline
\end{tabular}

Index: fractional logit models, clustered standard errors in parentheses, $\mathrm{p}<0.05,{ }^{* \star} \mathrm{p}<0.01$, ${ }^{\star \star \star} \mathrm{p}<0.001$ 
early-stage consultations, we do not observe a significant effect on the consultation HHI. Long-term strategy consultations, for instance, asking for input regarding what should be on the agency's agenda in the coming years, by comparison with implementation consultations, attract relatively more attention from nonbusiness interests and experts (but not other business interests). The predicted proportions of nonbusiness interests and experts decrease from $0.09(\mathrm{SE}=0.05)$ and 0.23 $(\mathrm{SE}=0.10)$ in early-stage consultations to $0.03(\mathrm{SE}=0.02)$ and $0.12(\mathrm{SE}=0.07)$ in late-stage consultations. These are small though significant differences, especially taking into account the small number of nonbusiness interests. Complexity has some impact on the consultation HHI. Table 5, Part III, illustrates that consultations announced by complexly written consultation calls decrease the relative number of nonbusiness interests participating. Their share among the consultees decreases from $0.07(\mathrm{SE}=0.05)$ consultations in response to a call written in layman's terms to $0.02(\mathrm{SE}=0.01)$ consultations in response to highly complex calls. Yet, we should remain cautious about these results. It should be noted that the size of the effect is rather small and nonbusiness mobilisation is mostly negatively affected by "very complex" issues, not "complex" issues. This means that, even for nonbusiness interests, mobilisation is only affected to a limited extent by perceived complexity. Even if agencies were to make some effort to communicate in a more accessible language, which might be recommended, this would not have a huge impact.

Considering the coefficient magnitudes and statistical significance, it is clear that contextual factors have a more pervasive impact compared to certain individual consultation characteristics. Looking at the main effects only (Table 5, Part I), it seems that only agency age matters, namely for older agencies the relative share of nonbusiness participation and the HHI increases. This suggests that older agencies attract a more diverse set of stakeholders, which confirms Hypothesis H6. Apparently, legal provisions and an agency's advisory committee do not have a direct impact. However, one could ask whether age and committee diversity matter most for agencies that are legally obliged to reach out to stakeholders. Such a moderating effect is plausible, as we know from other analyses that agency advisory committees bound by legal provisions are more diverse and provide more access to nonbusiness interests (Pérez Durán 2018). Table 5, Part II, illustrates that two interactions, testing whether legal provisions affect the impact of age or committee diversity, have a significant effect on the consultation $\mathrm{HHI}$ and the proportion of mobilised nonregulated interests. Although we have to be very cautious, especially because of the small number of agencies not bound by legal provisions, the results for agencies bound by legal provisions support the expectation that legal rules affect participation in consultations.

In order to aid interpretation, Figure la plots the estimated proportion of nonregulated consultees and the predicted HHI by agency. The advisory committee $\mathrm{HHI}$ and the agency age are presented on the $x$-axis. Considering the three agencies not bound by legal provisions, we can see that the mobilisation of nonregulated interests is very low (estimated proportion $<0.20$ ) in cases where the advisory committee is less diverse (the ACER and the EASA), while it is much higher for the ECHA. The ECHA has a much more diverse committee and higher estimated proportion (0.44) of nonregulated interests. In short, without legal provisions for stakeholder involvement, a less diverse advisory committee corresponds with less 
(a) $\longrightarrow$ HH consultations - - - non-regulated interests

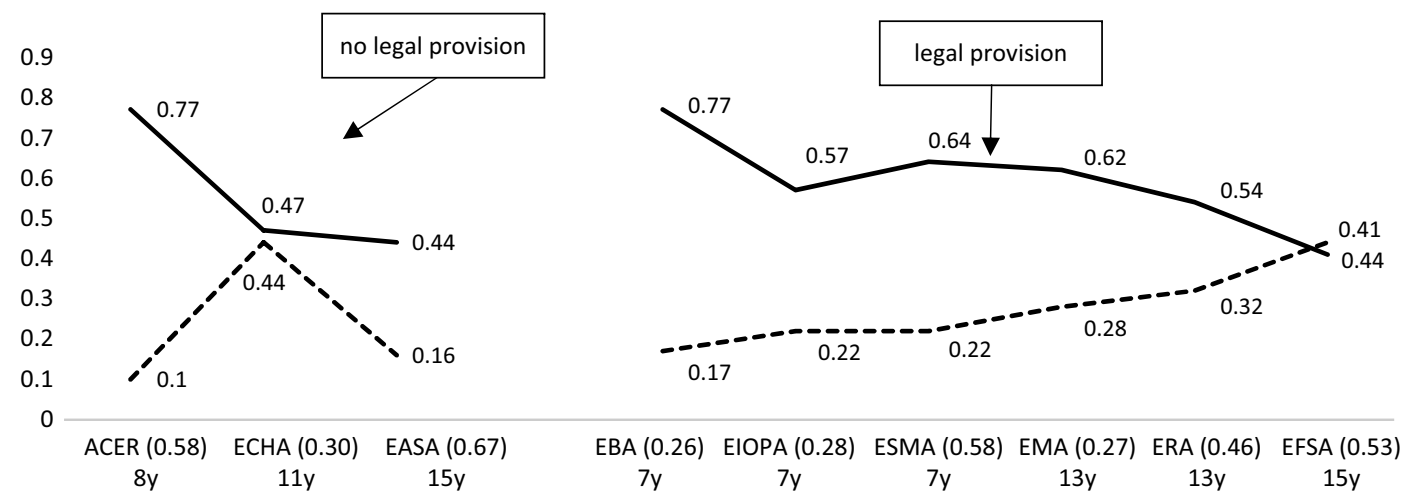

(b) - - - other business interests

non-business interests

experts

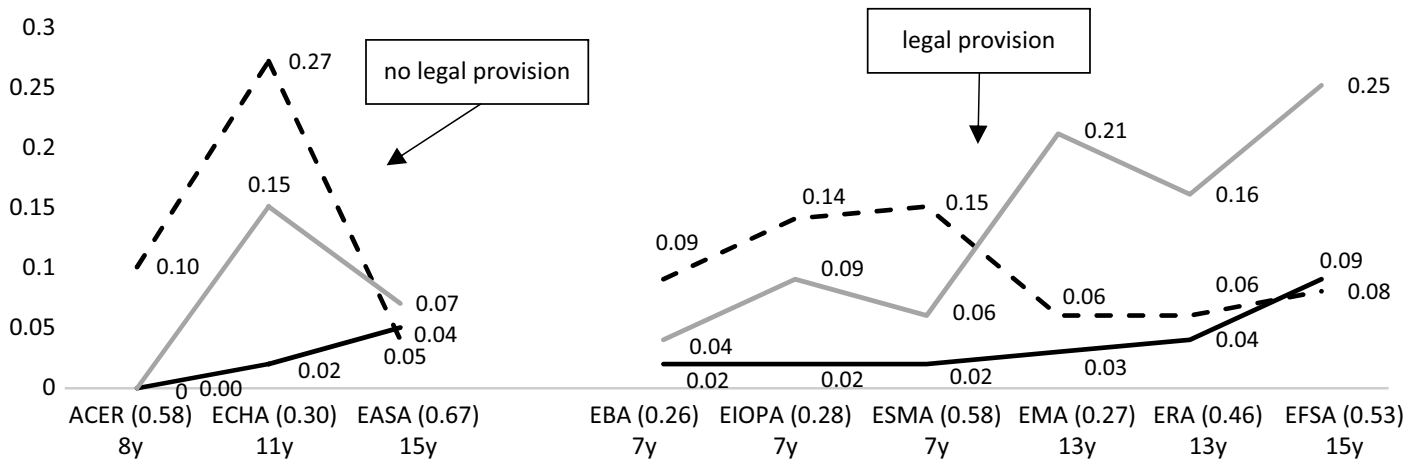

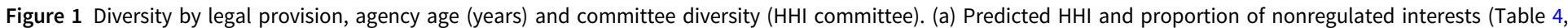
Part II). (b) Predicted proportion of other business, nonbusiness interests and experts (Table 4, Part III). 
nonregulated interests and lower diversity during consultations. Also, older agencies are characterised by more diverse consultations; the estimated HHIs for the ECHA and the ESA are 0.47 and 0.44, respectively, compared to 0.77 for the ACER.

The picture is slightly different for agencies bound by legal provisions, namely the participation of nonregulated interests increases (as well as the overall diversity during consultations) if the committees become less diverse (i.e. have a higher HHI). Agencies with a higher advisory committee HHI mobilise more nonregulated interests (estimated proportions are 0.41 for the EFSA and 0.32 for the ERA), compared to agencies with a higher committee HHI and not bound by legal provisions. The estimated proportions are perhaps less clear-cut for the ESMA; however, with its committee HHI of 0.64 and estimated proportion of nonregulated interests of 0.22 , the ESMA still mobilises a large number of nonregulated interests (compared to agencies not bound by legal provisions). Similar to agencies not bound by legal provisions, agency age positively affects the mobilisation propensity of nonregulated interests and leads to more diversity among consultation participants. However, it should be noted that agencies bound by legal rules are on average younger (more precisely the EBA, the EIOPA and the ESMA), and that these more recently established agencies have a lower estimated proportion of nonregulated interests and somewhat less diverse consultations compared to older agencies (the EMA, the ERA and the EFSA).

The interaction models reported in Table 5, Part III, largely confirm these results. Only the results for other business interests are different. Agency age does not affect the mobilisation of other business interests and, looking at the estimated proportions (Figure 1b), it seems that older agencies attract fewer other business interests (and relatively more nonbusiness interests and experts). Moreover, agencies bound by legal provisions attract far fewer other business interests (compared to agencies not bound by legal provisions), which is largely due to the very low mobilisation of other business interests in the case of the EMA (0.06), the ERA (0.06) and the EFSA (0.08). A closer look at the estimated proportions in Figure $1 \mathrm{~b}$ reveals another relevant result. One could ask which actor type contributes to consultation diversity. As agencies listed towards the right are more diverse, we find that diversity is largely due to an increasing number of experts and a decreasing number of other business interests (the EMA, the ERA and the EFSA). Although diversity corresponds with an increasing number of nonbusiness interests, the estimated share of nonbusiness interests in the entire range of mobilised stakeholders remains very low $(<0.10)$.

\section{Conclusion}

This article examined to what extent EU agency consultations are dominated by regulated industries or attract a more diverse set of stakeholders, and how varying participation patterns can be explained. The findings reveal that a large majority of the submissions agencies receive via public consultations come from regulated industries. Other stakeholders - nonbusiness interests, other business interests, experts and public authorities - mobilise in much smaller numbers. Even in the most diverse consultations $(\mathrm{HHI}<0.50), 69 \%$ of consultees represent regulated industries; in only $15 \%$ of consultations do nonbusiness interests comprise more than $10 \%$ of 
consultees. Although agencies have some discretion in how they design their consultations - open or closed format, complexity and stages of the policy process - consultation design factors have only a limited impact. Consultations announced by complexly written calls somewhat reduced the proportion of nonbusiness interests, but this effect was rather small; even the mobilisation of nonbusiness interests is affected only to a limited extent by perceived complexity.

In addition, consultations organised at the start of the policy cycle, that is, where the agency has an agenda-setting role, attract a wider range of stakeholders compared to consultations at the end of the policy cycle, that is, on implementation issues. This indicates that the implementation phase of EU regulation is fertile soil for regulated industries to mobilise, which is in line with previous research on stakeholder participation in consultations organised by US federal agencies (e.g. Yackee and Yackee 2006; Mckay and Yackee 2007; West and Raso 2013). This finding also confirms earlier observations demonstrating a higher prevalence of nonbusiness interests earlier in the policy process (e.g. Berkhout et al. 2018). Nonetheless, these varying mobilisation patterns should not be equated with regulated industries having less influence during earlier stages of the policy process. It is important that our results concern relative mobilisation patterns, namely compared to late-stage consultations, early-stage consultations attract relatively more nonbusiness interests (9\%), experts (18\%) and other business interests (8\%), which means that, in addition to public authorities (16\%), a substantial number of regulated industries $(48 \%)$ are still represented among the early-stage consultees.

Finally, compared to consultation design factors, contextual factors have a substantial impact. We found that legal provisions matter for consultation diversity; more precisely, legal rules interact significantly with agency age and the composition of agencies' advisory committees. This corroborates earlier findings on how stakeholder participation, but also access and potential influence, is not only a matter of stakeholders' own incentives to mobilise (so-called supply-side factors) but also shaped by the institutional setting policymakers establish for interactions with stakeholders (so-called demand-side factors) (Mahoney 2004; Kohler-Koch and Finke 2007; Quittkat 2011; Van Ballaert 2017).

Certainly, the limited number of agencies urges us to remain cautious. As EU agencies are established to regulate one particular policy field, it is difficult to draw conclusions with respect to policy field features. The opportunities for nonregulated interests to gain expertise and the extent to which knowledge is dispersed among different stakeholders are possibly influenced by policy-related variables. To regulate the banking sector, for example, regulators need information about the risks of certain financial products or a bank's assets, which is almost exclusively in the hands of banks themselves and difficult to acquire by other stakeholders. By contrast, food safety regulation requires information about the health risks of specific foods or ingredients, which can also be tested by regulators themselves, consumer organisations or independent scientists.

However, the fact that policies intersect with the institutional set-up of each agency makes it hard to separate policy characteristics from institutional features. Therefore, future research might take other agency-level or sector-specific characteristics into account, which might be useful given the substantial variation found between agencies and the effect of agency-level factors. Another useful avenue for 
future research would involve a more direct comparative analysis between agency consultations and consultations organised by the EC or other supranational/ national policymaking institutions. Analyses involving different institutions situated at multiple levels of governance would contribute to the development of a more general theoretical understanding of consultation practices. For instance, as much of agency politics concerns the implementation of legal rules, we observed a high propensity of regulated business to respond to consultation calls. Therefore, it is plausible to hypothesise that the consultation practices of EU regulatory agencies are more similar to consultations organised by national-level agencies than to EC consultations.

Two limitations of this study can inspire future scholarship on stakeholder mobilisation with regard to regulatory agencies. First, who participates in consultations is a subset of a larger stakeholder population with an interest in influencing the agencies (but see Rasmussen and Gross 2015; Berkhout et al. 2018; Røed and Wøien Hansen 2018). Therefore, the diversity of the consultation participants depends on how diverse the established interest group population is in the first place. For instance, the limited participation rate of NGOs in consultations on financial regulation seems to reflect a limited number of NGOs working on this topic, as the Finance Watch example at the start of this article illustrates. Open and lowthreshold consultations will have no or very little effect on diversity in stakeholder participation if organised counter-voices to the regulated industry do not exist. Future research should take into account these so-called supply-side factors and analyse who of the potential participants are the ones that mobilise. Second, stakeholder diversity in terms of group type does not necessarily imply diversity in terms of preferences. For instance, Young and Pagliari (2017) have observed strong business unity in regulatory processes on financial and energy issues, implying that the preferences of the regulated sector are often supported by other business interests. Moreover, diversity in terms of preferences articulated to policymakers does not guarantee more balanced policy outcomes. Future research should thus also investigate to what extent different preferences articulated in public consultations are reflected in the adopted regulations.

Acknowledgements. The research reported in this article benefited from a research grant of the Research Foundation-Flanders (G096512N) and the European Research Council (ERC-2013-CoG 616702-iBias). The authors thank Christel Koop, Caelesta Braun, Koen Verhoest, the three reviewers and the editor for a large number of constructive and helpful comments. We also thank Peter Aspeslagh and various anonymous student coders for excellent research assistance.

Data Availability Statement. Replication materials are available in the Journal of Public Policy Dataverse at https://doi.org/10.7910/DVN/KOP4D7.

\section{References}

Agné H, Dellmuth LM and Tallberg J (2015) Does Stakeholder Involvement Foster Democratic Legitimacy in International Organizations? An Empirical Assessment of a Normative Theory. Review of International Organizations, 10: 465-488.

Arras S and Braun C (2018) Stakeholders Wanted! Why and How European Union Agencies Involve Non-State Stakeholders. Journal of European Public Policy, 25: 1257-1275. 
Barkow RE (2010) Insulating Agencies: Avoiding Capture Through Institutional Design. Texas Law Review, 89: 15 (available at SSRN: https://ssrn.com/abstract=1717037).

Baumgartner FR and Jones BD (2015) The Politics of Information: Problem Definition and the Course of Public Policy in America. Chicago: The University of Chicago Press.

BEREC (2013) BEREC Guidelines on roaming regulation (EU) No. 531/2012 as amended by Regulation (EU) No. 2120/2015 (Excluding Articles 3, 4 and 5 on wholesale access and separate sale of services), goo.gl/Hh6t3m (accessed 8 February 2019).

Berkhout J, Beyers J, Braun C, Hanegraaff M and Lowery D (2018) Making Inference across Mobilization and Influence Research: Comparing Top-Down and Bottom-Up Mapping of Interest Systems. Political Studies, 66: 43-62.

Bernauer T and Gampfer R (2013) Effects of Civil Society Involvement on Popular Legitimacy of Global Environmental Governance. Global Environmental Change, 23: 439-449.

Beyers J, Dür A and Wonka A (2018) The Political Salience of EU Policies. Journal of European Public Policy, 25: 1726-1737.

Binderkrantz A, Pederson HH and Christiansen PM (2015) Interest Group Access to the Bureaucracy, Parliament, and the Media. Governance, 28: 95-112.

Borrás S, Koutalakis C and Wendler F (2007) European Agencies and Input Legitimacy: EFSA, EMeA and EPO in the Post-Delegation Phase. Journal of European Integration, 29: 583-600.

Bouwen P (2002) Corporate Lobbying in the European Union: The Logic of Access. Journal of European Public Policy, 9: 365-390.

Braun C (2012) The Captive or the Broker? Explaining Public Agency-Interest Group Interactions. Governance, 25: 291-314.

Braun C (2013) The Driving Forces of Stability Exploring the Nature of Long-Term Bureaucracy-Interest Group Interactions. Administration \& Society, 45: 809-836.

Broscheid A and Coen D (2007) Lobbying Activity and for a Creation in the EU: Empirically Exploring the Nature of the Policy Good. Journal of European Public Policy, 14: 346-365.

Bunea A (2017) Designing Stakeholder Consultations: Reinforcing or Alleviating Bias in the European Union System of Governance? European Journal of Political Research, 54: 46-69.

Bunea A and Thomson R (2015) Consultations with Interest Groups and the Empowerment of Executives: Evidence from the European Union. Governance, 28: 517-531.

Carpenter DP (2001) The Forging of Bureaucratic Autonomy: Reputations, Networks, and Policy Innovation in Executive Agencies, 1862-1928. Princeton: Princeton University Press.

Carpenter DP (2010) Reputation and Power: Organizational Image and Pharmaceutical Regulation at the FDA. Princeton: Princeton University Press.

Carpenter DP and Moss DA (2014) Preventing Regulatory Capture: Special Interest Influence and How to Limit it. Cambridge: Cambridge University Press.

Chalmers AW (2015) Financial Industry Mobilisation and Securities Markets Regulation in Europe. European Journal of Political Research, 54: 482-501.

Coen D and Thatcher M (2008) Network Governance and Multi-Level Delegation: European Networks of Regulatory Agencies. Journal of Public Policy, 28: 49-71.

Coglianese C (1997) Assessing Consensus: The Promise and Performance of Negotiated Rulemaking. Duke Law Journal, 46: 1255-1349.

Coglianese C, Zeckhauser R and Parson EA (2004) Seeking Truth for Power: Informational Strategy and Regulatory Policy Making. Minnesota Law Review, 89: 277-341.

Corporate Europe Observatory (2013) Unhappy Meal. The European Food Safety Authority's independence problem, goo.gl/CZT5Zw (accessed on 8 February 2019).

Damonte A, Dunlop CA and Radaelli CM (2014) Controlling Bureaucracies with Fire Alarms: Policy Instruments and Cross-Country Patterns. Journal of European Public Policy, 21: 1330-1349.

Dür A and Mateo G (2016) Insiders Versus Outsiders: Interest Group Politics in Multilevel Europe. Oxford: Oxford University Press.

Egeberg M and Trondal J (2011) EU-Level Agencies: New Executive Centre Formation or Vehicles for National Control? Journal of European Public Policy, 18: 868-887.

Egeberg M and Trondal J (2017) Researching European Union Agencies: What Have We Learnt (and Where Do We Go from Here)? Journal of Common Market Studies, 55: 675-690. 
EIOPA (2013) Discussion Paper on a Possible EU-Single Market for Personal Pension Products, goo.gl/AeQzli (accessed 8 February 2019).

Eising R (2007) The Access of Business Interests to EU Political Institutions: Towards Elite Pluralism? Journal of European Public Policy, 14: 384-403.

Finance Watch (2010) A Counter-Weight to the Lobbying Power of the Financial Industry. goo.gl/ceGdiJ (accessed 8 February 2019).

Furlong SR (1997) Interest Group Influence on Rule Making. Administration \& Society, 29: 325-347.

Furlong SR and Kerwin CM (2005) Interest Group Participation in Rule Making: A Decade of Change. Journal of Public Administration Research and Theory, 15: 353-370.

Gormley WT (1986) Regulatory Issue Networks in a Federal System. Polity, 18: 595-620.

Hanegraaff M (2015) Transnational Advocacy Over Time: Business and NGO Mobilization at UN Climate Summits. Global Environmental Politics, 15: 83-104.

Kelemen DR (2002) The Politics of "Eurocratic" Structure and the New European Agencies. West European Politics, 25: 93-118.

Klüver H (2012) Informational Lobbying in the European Union: The Effect of Organisational Characteristics. West European Politics, 35: 491-510.

Kohler-Koch B and Finke B (2007) The Institutional Shaping of EU-Society Relations: A Contribution to Democracy via Participation? Journal of Civil Society, 3: 205-221.

Kwak J (2014) Cultural Capture and the Financial Crisis. In Carpenter DP and Moss DA (eds.), Preventing Regulatory Capture: Special Interest Influence and How to Limit it. Cambridge: Cambridge University Press, 71-98.

Maggetti M (2007) De Facto Independence After Delegation: A Fuzzy-Set Analysis. Regulation \& Governance, 1: 271-294.

Mahoney C (2004) The Power of Institutions: State and Interest Group Activity in the European Union. European Union Politics, 5: 441-466.

Mattli W and Woods N (2009) In Whose Benefit? Explaining Regulatory Change in Global Politics. In Mattli W and Woods N (eds.), The Politics of Global Regulation. Princeton: Princeton University Press, 1-43.

McCarty N (2014) Complexity, Capacity, and Capture. In Carpenter DP and Moss DA (eds.), Preventing Regulatory Capture: Special Interest Influence and How to Limit it. Cambridge: Cambridge University Press, 99-123.

McCubbins MD and Schwartz T (1984) Congressional Oversight Overlooked: Police Patrols versus Fire Alarms*. American Journal of Political Science, 28: 165-179.

McKay A and Yackee SW (2007) Interest Group Competition on Federal Agency Rules. American Politics Research, 35: 336-357.

Moffitt SF (2010) Promoting Agency Reputation Through Public Advice: Advisory Committee Use in the FDA. Journal of Politics, 72: 880-893.

Novak WJ (2014) A Revisionist History of Regulatory Capture. In Carpenter DP and Moss DA (eds.), Preventing Regulatory Capture: Special Interest Influence and How to Limit it. New York: Cambridge University Press, 25-48.

Pagliari S and Young KL (2014) Leveraged Interests: Financial Industry Power and the Role of Private Sector Coalitions. Review of International Political Economy, 21: 575-610.

Pagliari S and Young KL (2016) The Interest Ecology of Financial Regulation: Interest Group Plurality in the Design of Financial Regulatory Policies. Socio-Economic Review, 14: 309-337.

Papke L and Wooldridge JM (1996) Econometric Methods for Fractional Response Variables With an Application to 401 (K) Plan Participation Rates. Journal of Applied Econometrics, 11: 619-632.

Peltzman S (1976) Toward a More General Theory of Regulation. The Journal of Law and Economics, 19: 211-240.

Pérez Durán I (2018) Interest Group Representation in the Formal Design of European Union Agencies. Regulation \& Governance, 12: 238-262.

Pfeffer J and Salancik G (1978) The External Control of Organizations - A Resource Dependence Perspective. New York: Harper \& Row Publishers.

Quittkat C (2011) The European Commission's Online Consultations: A Success Story? Journal of Common Market Studies, 49: 653-674. 
Quittkat C and Kotzian P (2011) Lobbying via Consultation - Territorial and Functional Interests in the Commission's Consultation Regime. Journal of European Integration, 33: 401-418.

Rasmussen A and Caroll BJ (2014) Determinants of Upper-Class Dominance in the Heavenly Chorus: Lessons from Online Consultations. British Journal of Political Science, 44: 445-459.

Rasmussen A and Gross V (2015) Biased Access? Exploring Selection to Advisory Committees. European Political Science Review, 7: 343-372.

Rittberger B and Wonka A (2011) Introduction: Agency Governance in the European Union. Journal of European Public Policy, 18: 780-789.

Røed M and Wøien Hansen V (2018) Explaining Participation Bias in the European Commission's Online Consultations: The Struggle for Policy Gain Without too Much Pain. Journal of Common Market Studies, doi: $10.1111 / \mathrm{jcms} .12754$

Schattschneider EE (1960) The Semisovereign People: A Realist's View of Democracy in America. New York: Holt, Rinehart and Winston.

Schlozman KL and Tierney JT (1986) Organized Interests and American Democracy. New York: Harper \& Row.

Stigler G (1971) The Theory of Economic Regulation. The Bell Journal of Economics and Management Science, 2: 3-21.

Thiel M (2014) European Civil Society and the EU Fundamental Rights Agency: Creating Legitimacy through Civil Society Inclusion? Journal of European Integration, 36: 435-451.

United Nations (2008) International Standard Industrial Classification of All Economic Activities (Series M No. 4/Rev.4). Department of Economic and Social Affairs, Statistics Department, goo.gl/8dw5k3 (accessed 8 February 2019).

Van Ballaert B (2017) The European Commission's Use of Consultation During Policy Formulation: The Effects of Policy Characteristics. European Union Politics, 18: 406-423.

West WF and Raso C (2013) Who Shapes the Rulemaking Agenda? Implications for Bureaucratic Responsiveness and Bureaucratic Control. Journal of Public Administration Research and Theory, 23: 495-519.

Wonka A and Rittberger B (2010) Credibility, Complexity and Uncertainty: Explaining the Institutional Independence of 29 EU Agencies. West European Politics, 33: 730-752.

Wonka A, Baumgartner FR, Mahoney C and Berkhout J (2010) Measuring the Size and Scope of the EU Interest Group Population. European Union Politics, 11: 463-476.

Yackee JW and Yackee SW (2006) A Bias Towards Business? Assessing Interest Group Influence on the U.S. Bureaucracy. The Journal of Politics, 68: 128-139.

Yackee SW (2006) Sweet-Talking the Fourth Branch: The Influence of Interest Group Comments on Federal Agency Rulemaking. Journal of Public Administration Research and Theory, 16: 103-124.

Yackee SW (2013) Assessing Regulatory Participation by Health Professionals. Public Administration Review, 73: 105-114.

Yackee SW (2014a) Participant Voice in the Bureaucratic Policymaking Process. Journal of Public Administration Research and Theory, 25: 427-449.

Yackee SW (2014b) Reconsidering Agency Capture During Regulatory Policymaking. In Carpenter DP and Moss DA (eds.), Preventing Regulatory Capture: Special Interest Influence and How to Limit it. Cambridge: Cambridge University Press, 292-325.

Young K and Pagliari S (2017) Capital United? Business Unity in Regulatory Politics and the Special Place of Finance. Regulation \& Governance, 11: 3-23.

Cite this article: Beyers J and Arras S (2020). Who feeds information to regulators? Stakeholder diversity in European Union regulatory agency consultations. Journal of Public Policy 40, 573-598. https://doi.org/ $10.1017 /$ S0143814X19000126 